\title{
Rachele Branchini, Les Jumeaux d'Agota Kristof ou les masques ironiques du déracinement
}

\section{Riccardo Benedettini}

\section{(2) OpenEdition}

1 Journals

\section{Edizione digitale}

URL: http://journals.openedition.org/studifrancesi/5776

DOI: $10.4000 /$ studifrancesi.5776

ISSN: 2421-5856

\section{Editore}

Rosenberg \& Sellier

\section{Edizione cartacea}

Data di pubblicazione: 1 septembre 2011

Paginazione: 459-460

ISSN: 0039-2944

\section{Notizia bibliografica digitale}

Riccardo Benedettini, «Rachele Branchini, Les Jumeaux d'Agota Kristof ou les masques ironiques du déracinement», Studi Francesi [Online], 164 (LV | II) | 2011, online dal 30 novembre 2015, consultato il 11 janvier 2021. URL: http://journals.openedition.org/studifrancesi/5776 ; DOI: https://doi.org/10.4000/ studifrancesi.5776

Questo documento è stato generato automaticamente il 11 janvier 2021.

\section{(c) $(1)$}

Studi Francesi è distribuita con Licenza Creative Commons Attribuzione - Non commerciale - Non opere derivate 4.0 Internazionale. 


\title{
Rachele Branchini, Les Jumeaux d'Agota Kristof ou les masques ironiques du déracinement
}

\author{
Riccardo Benedettini
}

\section{NOTIZIA}

RACHELE BRANCHINI, Les Jumeaux d'Agota Kristof ou les masques ironiques du déracinement, in Exilées, expatriées, nomades..., «Francofonia», 58, primavera 2010, pp. 45-54.

1 Da un esergo che rinvia all'ironia studiata da Jankélévitch, l'A. applica una propria particolare interpretazione del meccanismo ironico ad alcuni momenti della produzione letteraria di Kristof. In un'analisi scandita in cinque fasi (L'Ironie: de l'expression au silence, S'éloigner de la langue, s'éloigner des choses, La Désinfection, Les Jumeaux: le "nous" comme prise de distance du "je", Une analphabète déracinée), e che ricorre anche ai «Manuscrits du Grand Cahier» - alcuni Inediti sono pubblicati in questo stesso volume della rivista (pp. 165-170) -, la Branchini si sforza di mettere in evidenza il «chemin qui, de l'expression ironique» (p. 54) conduce i personaggi «vers le silence du cynisme». Silenzio che sembra accomunare i personaggi stessi al loro autore dato che, leggiamo, «après le dernier tome de La Trilogie, Agota Kristof n'écrira plus rien» (p. 47). Contrariamente a quanto qui (come in altri luoghi del testo: «l'édition définitive de $L a$ Trilogie», p. 49) si avanza, pur ricordando le differenti «dates de publication des trois romans» (p. 49), segnaliamo che l'espressione «Trilogia» (o «Trilogie») non deve costituire il rinvio ad un'opera così pensata e voluta dalla scrittrice (i tre romanzi, e in particolare Le Grand cahier, possono essere letti in maniera del tutto autonoma gli uni dagli altri) bensì una definizione terminologica innanzitutto editoriale (si pensi al volume Trilogia della Città di K. pubblicato nel 1998 presso l'editore Einaudi mentre, ad esempio, di «trilogie» non parlava Seuil, nel volume unico edito nel 1991 dove si conserva il sottotitolo, variato al plurale, di romans), scelta "economica" che solo in un secondo tempo influenza la ricezione pubblica, ivi compresa quella della "lettura" 
critica. Ricordiamo inoltre che dopo Le Troisième mensonge, terzo momento della "trilogia", Kristof pubblica, nel 1995, un altro romanzo, Hier, in Italia ben noto anche grazie alla trasposizione cinematografica Brucio nel vento (2001), di Silvio Soldini. 